\title{
Eröffnung der Tagung am 10. Oktober 1957
}

Vor Eintritt in die wissenschaftlichen Beratungen, die im Plenarsaal des Bundesverwaltungsgerichts stattfanden, begrüßte der Vorsitzende der Vereinigung, Herr $S \mathrm{ch} u ̈ l e$, die erschienenen Mitglieder und Gäste.

Er gedachte auch des am 26. Juni 1957 verstorbenen Ehrenpräsidenten der Vereinigung, Geheimrat Prof. Dr. Richard Th o m a, und führte hierbei $u$. a. folgendes aus:

„Richard Thoma war eine Persönlichkeit von seltener Art und hohem Rang. Er vereinigte in sich eine Vielheit schöner Eigenschaften: Verstand und Gemüt, einen klaren Kopf, zugleich ein überaus warmes Herz; kritisches Urteil auf der einen, Bereitschaft zum Verstehen auf der anderen Seite; ernsten Sinn, Maß im Schauen und Wägen, Heiterkeit wie Gelassenheit - all das und vieles andere fand sich bei ihm in glücklicher Ausgewogenheit und ergab jene wohltuende Harmonie der Persönlichkeit, die jeder spürte, der ihm einmal begegnete. Humanität und Liberalität waren die Kennzeichen seines Wesens. Sie waren auch die großen Leitsterne, die seinem Leben und Schaffen vorgeleuchtet haben. Ein feinsinniger Geist, ein untadeliger Mensch, ein gütiger Freund gegenüber allen ist mit ihm geschieden.

Was er unserer Wissenschaft gewesen ist, was er ihr während eines langen arbeitsamen Lebens geschenkt hat, kann an dieser Stelle nicht ausgebreitet werden es wäre das wohl auch kaum in seinem Sinn. Das Wich-tigste darf aber doch gesagt werden, um seine Bedeutung in der jüngeren Geschichte unserer Wissenschaft festzuhalten. Er steht in ihr verzeichnet als eines der großen Bindeglieder zwischen Vergangenheit und Gegenwart. Gelernt und seine ersten wissenschaftlichen Sporen verdient hat er gegen Ende der konstitutionellen Epoche. In der Weimarer Periode wurde er zu einer der tragenden Figuren der deutschen Staatsrechtswissenschaft, und es war ihm vergönnt, noch in die Zeit nach 1945 hinüberzuwirken. Zunächst nochmals tätig eingreifend in die Auseinandersetzungen um die Gestaltung der Verfassung, um die Neuordnung der Universität und allgemein in die wissenschaftlichen Erörterungen unseres Faches, dann 
aber, von den Lasten des Alters nicht verschont, mehr und mehr schauend und empfangend.

So darf Richand Thoma gesehen werden. Wir, die wir zurückgeblieben sind, haben sein wissenschaftliches Werk, haben auch sein menschliches Erbe zu wahren. Die Vereinigung der Deutschen Staatsrechtslehrer wird ihren verewigten Ehrenpräsidenten niemals vergessen."

Der Vorsitzende widmete ferner dem im Jahre 1956 allzu

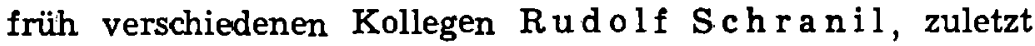
o. Professor der Rechte an der Universität des Saarlandes, herzliche Worte des Gedenkens.

Abschließend wies der Vorsitzende darauf hin, daß die Vereinigung vor nunmehr 35 Jahren errichtet worden sei. Die Gründungsversammlung habe, wenn er recht unterrichtet sei, in demselben Gebäude stattgefunden, in dem die Vereinigung auch jetzt wieder tage.

Der Vorsitzende übergab dann das Wort an den Präsidenten des Bundesverwaltungsgerichts, Eg i di, der die Teilnehmer mit folgender Ansprache begrüßte:

„Meine sehr geehrten Herren!

In meiner Eigenschaft als Hausherr dieser Räume darf ich zunächst meiner aufrichtigen Freude Ausdruck geben, daB Sie sich entschlossen haben, als Ort Ihrer Tagung dieses Haus zu wählen, das auf dem Gebiet der Verwaltungsgerichtsbarkeit die Tradition eines halben Jahrhunderts umschließt.

Einer der Ihren ist es gewesen, Rudolf von Gneist, der durch sein unerschütterliches Wirken praktisch die Verwaltungsgerichtsbarkeit ins Leben gerufen hat. Sie ist sich dessen bewußt, dankbar bewußt, daß sie - jedenfalls in Preußen - ihr Dasein diesem einen Manne schuldet, ihr Sonder-Dasein, wie im Hinblick auf die Erörterungen des letzten deutschen Juristentages hinzugesetzt werden mag. Nicht ohne Grund hat seine Büste die Eingangshalle vor diesem Saale lange Zeit geziert. Denn sein Geist hat die Formen erdacht und vorgeprägt, deren sich der Gesetzgeber später bedient hat. Es sind dieselben Formen, in denen die Verwaltungsgerichtsbarkeit nach dem Neubeginn der Jahre 1945/1946 sich lebendig weiterentwickelt und ausgebreitet hat.

Der Weg, den die Verwaltungsgerichtsbarkeit in den Jahrzehnten seit ihrer Begründung durchlaufen hat, wird in besonderer Weise dadurch gekennzeichnet, daB Wissenschaft und Praxis stets aufs engste zusammengear- 
beitet haben. Es läßt sich schlechterdings wohl nicht entscheiden, wer dabei in höherem Grade der Gebende, wer der Nehmende war. Es hat in der Vergangenheit geradezu leuchtende Beispiele harmonischen Zusammenspieles gegeben, wie dieses etwa Ausdruck findet in der unmittelbaren persönlichen Mitwirkung von Rechtslehrern in den Kollegien der Verfassungs- und der Verwaltungsgerichte, aber auch in manch anderer Weise stattgefunden hat. Wenn ich den Namen $O$ t to $M$ a yer für eine frühere Vergangenheit und die Namen Walter Jellinek und Carl Sartorius für die spätere Vergangenheit nenne, so bedeutet das in unserem Kreise mehr als die Beschwörung teurer Schatten. Sie wollen daraus vielmehr den Wunsch entnehmen, da $B$ auch in der Gegenwart und in der Zukunft eine ähnlich erfolgreiche Arbeitsteilung hergestellt werden möge. In diesem Sinne wünsche ich Threr Tagung einen erfolgreichen Verlauf.

Lassen Sie mich indessen bei dieser besonderen Gelegenheit noch ein offenes Wort über ein delikates Thema anfügen. Nun einmal der Name $G n$ is t gefallen ist, darf wohl auch der Gedanke ausgesprochen werden, daß die Schaffung einer selbständigen Verwaltungsgerichtsbarkeit gerade auch einigen seiner „fruchtbaren Irrtümer" zuzuschreiben ist. Derlei gibt es! Dieses Gericht ist der Kritik seitens der Wissenschaft in der kurzen Zeit seines Bestandes ausgesetzt gewesen, wie das nicht anders zu erwarten war. Sie war teils günstig, teils ungünstig; auch das kann nicht überraschen. In beiden Fällen haben wir die Kritik in der Regel dankbar begrüßt. Wir sind nicht nur darauf gefaßt, wir vermissen es geradezu, wenn das Echo ausbleibt! Freilich hat es sich dann und wann ereignet, daß wir im Widerhall die eigene Stimme kaum wiedererkannt haben: Wenn wir unsererseits schon dem Irrtum ausgesetzt sind und der entsprechenden Kritik Ihrerseits, dann lassen Sie mich und meine Herren nicht der Zuversicht entraten, daß im Wechselgespräch von Theorie und Praxis der Austausch von Meinung und Gegenmeinung sich stets fruchtbar erweisen möge. Der Wertschätzung und des Vertrauens unsererseits dürfen Sie gewiß sein." 
